\title{
Saccular aneurysm caused by bacterial endocarditis in a syphilitic aorta
}

\author{
W. M. ROBINSON ${ }^{1}$, I. K.R. MCMILLAN ${ }^{2}$, and A. M. JOHNSON \\ Wessex Cardiac and Thoracic Centre, Southampton Western Hospital
}

\begin{abstract}
Robinson, W. M., McMillan, I. K. R., and Johnson, A. M. (1973). Thorax, 529-532. Saccular aneurysm caused by bacterial endocarditis in a syphilitic aorta. The rapid development of a saccular aneurysm during successfully treated bacterial endocarditis, in an ascending aorta previously affected by syphilis which had been treated with adequate chemotherapy 15 years previously, is described. Although bacterial endocarditis does occasionally complicate syphilitic aortic valve disease, the literature does not contain any report of resulting aneurysm development. The investigation and successful surgical treatment of the case are described.
\end{abstract}

The development of saccular aneurysm of the thoracic aorta following syphilitic infection has long been recognized and Kampmeier (1938) found that $93 \%$ of aneurysms in this site were of luetic origin. More recent surveys by Roberts, Danielson, and Blakemore (1957) and Carlsson and Sternby (1964) showed that the proportion decreased to $50 \%$ and $26 \%$ respectively. In these and other reports of large clinical and pathological studies concerning cardiovascular syphilis (Colt, 1927 ; Welty, 1939 ; MacFarlane, Swan, and Irvine, 1956 ; Heggtveit, 1964) no mention is made of the possibility of bacterial endocarditis as a cause of aortic aneurysm formation.

There are several reports of bacterial infection involving the luetic aortic valve. Aceves, Elizalde, and González Luna (1957) found this in 9 out of 100 necropsies of subjects with syphilitic aortic valve disease and Martin and Adams (1938) described five such cases.

The patient now reported was known to have had syphilitic aortitis with aortic regurgitation for at least $\mathbf{1 5}$ years prior to this admission to hospital, when he was diagnosed as suffering from bacterial endocarditis. During treatment for this, a saccular aneurysm of the ascending aorta was seen to develop.

\section{CASE REPORT}

A 48-year-old non-commissioned officer of AngloIndian descent was admitted to the Military Hospital, Tidworth on 14 October 1970 suffering from angina,

1Present address: Lt. Colonel W. M. Robinson, The Queen Alexandra Military Hospital, Millbank, London S.W.1

2Request for reprints to I.K.R.McM. fever, and lethargy for the previous four days. Seropositive syphilitic aortitis with valvular incompetence was diagnosed in 1955, though venereal disease was denied. He had subsequently received courses of treatment with penicillin in adequate doses. Three weeks prior to admission teeth were extracted without antibiotic protection.

On examination he was febrile and the signs of regurgitation without left ventricular failure were found. The blood pressure was $160 / 55 \mathrm{mmHg}$. No evidence of bacterial embolic phenomena was seen in the skin or nail beds but there was microscopic haematuria.

INVESTIGATION AND TREATMENT Haemoglobin $13.2 \mathrm{~g} /$ $100 \mathrm{ml}$; white cell count $13,800 / \mathrm{mm}^{3}$; neutrophils $77 \%$; lymphocytes $14 \%$; monocytes $8 \%$; eosinophils $1 \%$. Erythrocyte sedimentation rate $105 \mathrm{~mm}$ fall in 1 hour. Electrocardiogram: Sinus rhythm with normal $P$ wave and PR interval; QRS normal in duration and frontal axis $\left(+45^{\circ}\right)$ but increased $R$ wave voltage and flat $T$ waves in left chest leads.

Venereal diseases reference laboratory (VDRL) test: negative. Reiters protein complement fixation test (RPCFT): positive 1:16. Treponema pallidum immobilization (TPI) test: negative. Fluorescent treponemal antibody (FTA) test: positive. Samples of venous blood taken at hourly intervals for culture under aerobic and anaerobic conditions proved to be sterile.

A chest radiograph showed only slight enlargement of the ascending aorta with calcification but no evidence of a saccular aneurysm.

A clinical diagnosis of subacute bacterial endocarditis complicating luetic aortic valve disease and aortitis was made, and benzyl penicillin, $48 \mathrm{~g}$ per 24 hours, was given by the intravenous route. He became afebrile on the third day and treatment was 


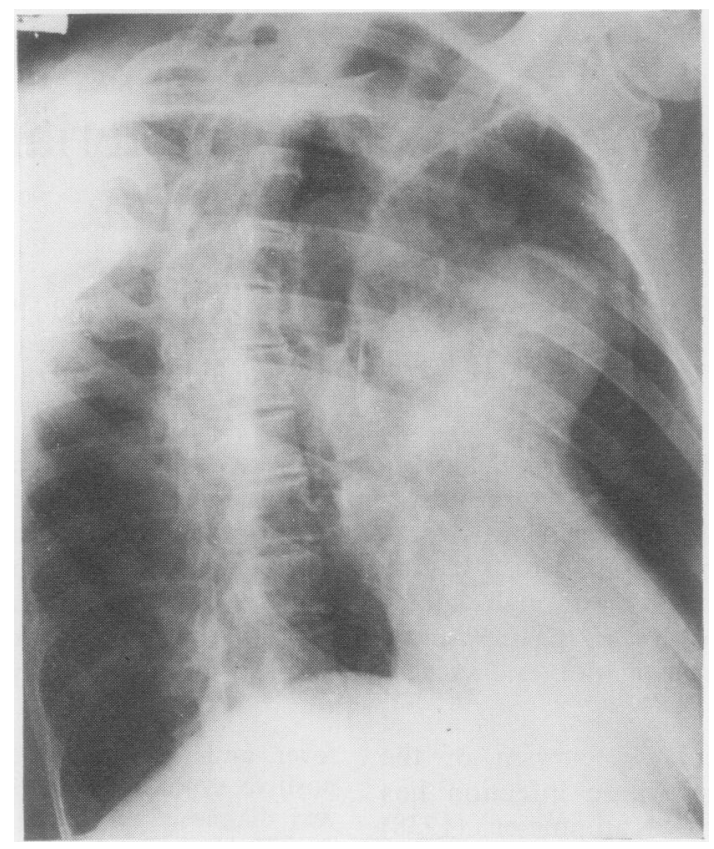

FIG. 1. Oblique film to show aneurysm.

continued for six weeks. The degree of aortic regurgitation was unchanged, but pulsation became visible in the second left intercostal space immediately lateral to the sternum, and the chest film (Fig. 1) revealed a saccular aneurysm of the ascending aorta. Five days later, on 10 December 1970, he was transferred to the Wessex Cardiac and Thoracic Centre where another chest film showed that the aneurysm was larger. On 11 December cardiac catheterization, cine aortography, and biplane aortography were performed. Severe aortic regurgitation was confirmed but there was no left ventricular failure. The exact site of the saccular aneurysm was shown (Fig. 2). It was decided that the sac should be resected and the aortic valve replaced without delay.

OPERATION On 16 December 1970, under general anaesthesia, the left femoral artery and vein were cannulated and the patient was heparinized. Through a midline sternotomy the aneurysm was found to be arising from the anteromedial aspect of the ascending aorta and directed to the left, as had been seen in the aortograms. The mediastinal layers were removed from over the aneurysm without trouble. The superior vena cava was cannulated from the right atrium and the inferior vena cava via the left femoral vein and perfusion was begun. While the oesophageal temperature was steadily reduced to $26^{\circ} \mathrm{C}$ further mobilization of the aneurysm was achieved. The whole ascending aorta contained eggshell calcification. The aorta was mobilized and a tape was passed around it just proximal to the innominate artery and above the aneurysm. At this stage ventricular fibrillation occurred; the aorta was cross-clamped because of gross aortic regurgitation, and the left ventricular vent was inserted. The aneurysm was then opened and was found to be full of blood clot. Its wall was heavily calcified and showed numerous vegetations, especially at its mouth. It was resected as widely as possible by lateral aneurysmorrhaphy and the defect was closed with two layers of 00 Ethiflex sutures. This procedure had taken 25 minutes and the aortic 을 clamp was then released for a short period. It was $D$ then reapplied and the aorta was opened by an 음 oblique incision immediately above the valve. Two of the commissures were found to be fused and the $\mathscr{S}$ valve was grossly incompetent. It was replaced with $N$ a size 12 Starr-Edwards metal ball prosthesis sewn into position with interrupted Tefdec 00 sutures. This $\omega$ procedure was accomplished using intermittent left and right coronary artery perfusion and it was noted $\varrho$ that the coronary ostia were normal in size. The $\mathbb{D}$ aortic incision was closed using two layers of con- \& tinuous Tefdec sutures. The patient was rewarmed 0 and the heart was defibrillated satisfactorily. The $\bar{O}$ patient was then weaned off perfusion, the heart took $\overrightarrow{\mathbb{D}}$ over well, and the prosthetic valve was competent. $\frac{\rho}{\mathbb{Q}}$ When conditions were stable the venous tubes were $\varrho$ removed and protamine was given. Finally the ascending aorta was wrapped circumferentially in $\Omega$ 

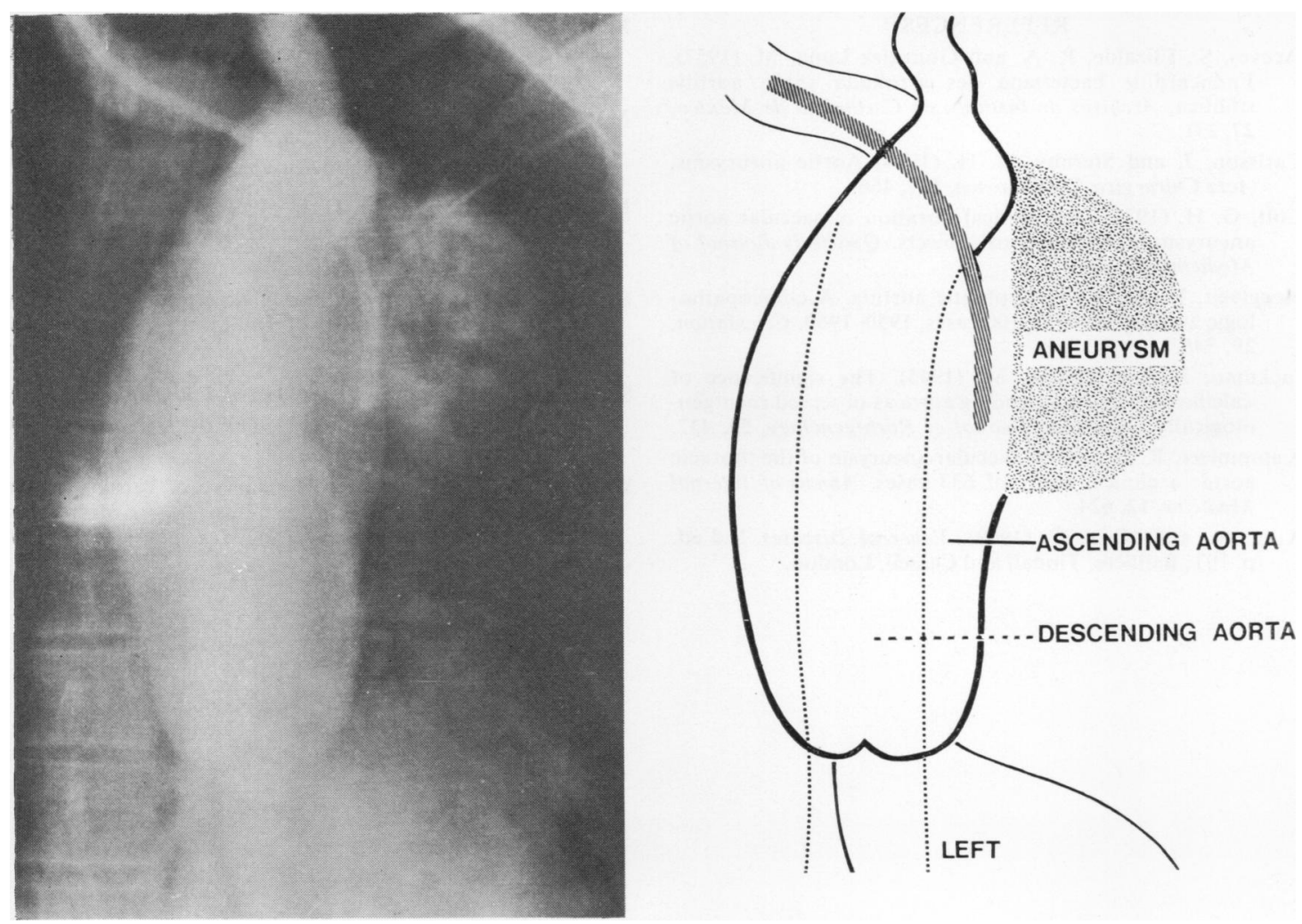

FIG. 2. Oblique aortogram to show aneurysm (diagram same scale).

Teflon felt. The pericardium was loosely closed and the wound was repaired in the usual way with drainage. Total perfusion time had been 2 hours 50 minutes.

Postoperative progress was uneventful and the patient left hospital after five weeks. Histology of the aneurysm wall was compatible with a syphilitic aneurysm. Sections of one of the vegetations showed collagenous fibrous tissue containing amorphous debris and an admixture of acute inflammatory cells. No organisms were identified after special staining, and culture of the aneurysm showed no growth. In August 1972 the patient was well, with normal function of the prosthetic valve and no evidence of recurrence of the aneurysm. He was performing his normal military clerical duties.

\section{DISCUSSION}

That this patient had cardiovascular syphilis was clinically certain in the presence of positive serology and the finding of calcification of the ascending aorta, as described by Snellen (1939), Jackman and Lubert (1945), and McCann and
Porter (1956). The serology results were consistent with the history of syphilis and did not indicate active disease, $50 \%$ of patients with late syphilis showing similar findings (King and Nicol, 1969).

The aneurysm was seen to develop in less than six weeks in the presence of clinically diagnosed bacterial endocarditis and was observed to increase in size at a pace more rapid than is usual in a purely luetic aneurysm. Colt (1927) found that the average survival time after diagnosis of aneurysm was 18 months. It is of interest also that Welty (1939), in a necropsy survey of cardiovascular syphilis, found aortic valve incompetence and saccular aneurysm co-existing in only $15 \%$ of cases.

Reports by Martin and Adams (1938) and affecting the aorta and aortic valve support the Aceves et al. (1957) of bacterial endocarditis aetiological diagnosis put forward in this case.

The authors wish to thank Dr. J. M. Manners, Dr. E. S. Machell, and Lt.-Col. I. Michie, RAMC, for help in the management of this patient. 


\section{REFERENCES}

Aceves, S., Elizalde, R. A. and González Luna, M. (1957). Endocarditis bacteriana des arrollada sobre aortitis sifilitica. Archivos de Instituto de Cardiolgía de México, 27, 231.

Carlsson, J. and Sternby, N. H. (1964) Aortic aneurysms. Acta Chirurgica Scandinavica, 127, 466.

Colt, G. H. (1927). The clinical duration of saccular aortic aneurysm in British-born subjects. Quarterly Journal of Medicine, 20, 331.

Heggtveit, H. A. (1964). Syphilitic aortitis. A clinicopathologic autopsy study of 100 cases, 1950-1960. Circulation, $29,346$.

Jackman, J., and Lubert, M. (1945). The significance of calcification in the ascending aorta as observed roentgenologically. American Journal of Roentgenology, 53, 432.

Kampmeier, R. H. (1938). Saccular aneurysm of the thoracic aorta: a clinical study of 633 cases. Annals of Internal Medicine, 12, 624.

King, A., and Nicol, C. (1969). Venereal Diseases, 2nd ed. p. 103 ; Baillière, Tindall and Cassell, London.
Martin, H. E., and Adams, W. L. Jr. (1938). Bacterial endocarditis superimposed on syphilitic aortitis and valvulitis. American Heart Journal, 16, 714.

MacFarlane, W. V., Swan, W. G. A., and Irvine, R. E (1956). Cardiovascular disease in syphilis. A review of 1,330 patients. British Medical Journal, 1, 827.

McCann, J. S., and Porter, D. C. (1956). Calcification of the aorta as an aid to the diagnosis of syphilis. British Medical $\vec{\circ}$ Journal, 1, 826.

Roberts, B., Danielson, G., and Blakemore, W. S. (1957). Aortic aneurysm, Report of 101 cases. Circulation, 15, 483.

Snellen, H. A. (1939). In Year Book of Radiology, edited by $\infty$ C. A. Waters, W. B. Firor, and I. I. Kaplan. Year Book Publishers, Chicago.

Welty, J. W. (1939). A necropsy survey of cardiovascular syphilis with particular reference to its decreasing incidence. American Journal of Medical Sciences, 197, 782. 